\title{
Interventions for Youth at Risk of Bipolar Disorder
}

\section{Anne Duffy, MSC, MD, FRCPC}

\author{
Address \\ Department of Psychiatry, Mathison Centre for Mental Health Research \& Education, \\ Hotchkiss Brain Institute, University of Calgary, 3280 University Ave, NW, TRW \\ Building, 4th Floor, Calgary, Alberta, Canada T2N 4N6 \\ Email: acduffy@ucalgary.ca
}

Published online: 14 January 2014

C) Springer International Publishing AG 2014

Keywords High-risk - Bipolar disorder - Mood disorders - Treatment - Early intervention • Prevention - Clinical staging . Novel treatment · Adolescent · Nutraceuticals · Antioxidants · Antidepressants · Mood stabilizers · Lithium

\section{Opinion statement}

With the recognition that bipolar disorder (BD) develops in a series of predictable clinical stages, clinical and research focus has shifted increasingly into early intervention and prevention. The heritability of BD is estimated to be around $85 \%$; therefore, children of affected parents are an identifiable and important high-risk group. Lessons from early psychosis and other areas of medicine suggest that education for high-risk families regarding recognizable clinical stages and modifiable risk factors are a reasonable starting place. Specifically, reinforcing the importance of healthy nutrition, cardiovascular exercise, maintaining normal body mass index, and healthy coping strategies are important topics to cover. Early risk syndromes include sleep and anxiety disorders, which should be addressed with low-risk treatments, including sleep hygiene and individual psychotherapy. Typically, adolescence marks the age of onset of depressive disorders related to the bipolar diathesis. This is also the time when poor coping through substance abuse emerges. It is very important when assessing a depressed adolescent to understand the familial risk of psychiatric disorders. While psychotherapy is typically effective for mild non-psychotic depression, the acute treatment of moderate-severe major depression in adolescents and young adults with a confirmed family history of BD is a topic of considerable debate. The treatment decision should be taken together with the patient and family, with full discussion of the risks and potential benefits. Options include a closely monitored trial of low-dose antidepressant, discontinued immediately upon resolution of the depressive episode, or mood stabilizer that fits the patient profile, or a combination of these two, in addition to psychotherapy and reducing modifiable risk factors. When a high-risk subject manifests a diagnosable manic or hypomanic episode (typically years after the first depressive episode in late adolescence or adulthood) the question arises of whether to initiate prophylactic treatment. Potential candidates are those with a high recurrence risk and/or concern about the recurrence of a severe episode. Research has shown that most patients can be stabilized, with selected monotherapy individualized on the basis of the nature of the clinical course (episodic vs. non-episodic), quality of the spontaneous remission, and family history of psychiatric disorders and treatment response. 
Novel adjunctive treatments including nutraceuticals, antioxidants, and anti-inflammatory agents are being studied and may be helpful in high-risk individuals during the early stages of illness development.

\section{Introduction}

Psychiatry is undergoing a paradigm shift in the approach to diagnosis and treatment. The early-intervention movement is rooted in schizophrenia research pioneered by McGorry and colleagues $[1 \bullet \bullet]$, which highlighted the critical need and benefits of identifying psychiatric disorders earlier in the illness course. In parallel, neurobiological research aimed at understanding the pathophysiology of major psychiatric disorders, including bipolar disorder (BD), has advanced our understanding of biological markers associated with illness activity and helped to identify possible early-intervention targets [2•]. Collectively, the developmental early-intervention approach to diagnosis, coupled with assessment and monitoring of important risk factors and illness activity indicators, will move us toward improved individualized diagnosis, treatment planning, and response monitoring. Happily, based on overwhelming evidence, we appear to be ready to abandon the current approach to diagnosis that emphasizes cross-sectional assessment of non-specific overlapping symptoms while neglecting other important information, such as the individual patient's clinical course, family history of psychiatric disorder and treatment response, and psychosocial and biological risk factors. The status quo yields broad heterogeneous diagnostic categories, with no utility in predicting outcome or treatment response and completely unsuited toward advancing our understanding of the onset and progress of psychiatric disorders in vulnerable individuals [3•].

This paper aims at providing a brief overview of the clinical course of $\mathrm{BD}$ from high-risk status to illness onset and progression. Following this, treatment implications based on the recent advances in our understanding of the natural history of $\mathrm{BD}$ and pathophysiology are discussed, with particular emphasis on high-risk individuals.

\section{Observations in patients with established illness}

Prospective and retrospective studies of individuals diagnosed with $\mathrm{BD}$, as well as large epidemiology studies, support typical BD onset starting in adolescence and usually peaking in early to mid-adulthood $[4-6,7 \bullet]$. The history leading to the current $\mathrm{BD}$ diagnostic construct has been reviewed extensively and is beyond the scope of this paper (see $[8,9 \bullet])$. However, common to all historical descriptions of classical manic-depressive illness is the recurrent nature of the spontaneous illness course. The frequency of recurrence varies greatly between individual patients, and the patient's own spontaneous course is the best predictor of future recurrence risk and cycle length (free interval) [8]. The observation of severe depressive episodes alternating with activated hypomanic or manic episodes, often associated with the same indicators of dysfunctions of central feedback mechanisms and brain arousal, have mystified clinicians and researchers alike. Furthermore, patients vary greatly in the proportion of depressed compared to activated episodes over the life course, and it is unclear what factors determine an individual's course of illness. What we do know is that women tend to have a higher depressive/activated ratio, and untreated, the illness continues with lifelong remittance and recurrence and complications of substance abuse and very high rate of suicide [8, 10-12].

More recently, there has been a reconceptualization of $\mathrm{BD}$ as a chronic illness, with progressively reduced cycle lengths (remissions) and significant residual symptoms. These observations support the view that

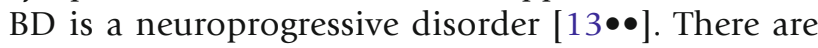
several reasons why the understanding of the natural history of the disorder has shifted in this way, including the fact that the diagnostic category has been broadened and includes psychotic and personality disorders not historically included in the diagnosis $[14 \bullet, 15]$. Furthermore, BD patients (typical or otherwise) have a very high risk of developing complicating substance use and medical disorders (cardiovascular, metabolic syndrome, cancer) that likely contribute to poorer outcomes and reduced quality of remission [16]. Generic treatment guidelines do not match the patient profile to the treatment approach, and contribute not only to reduced success in both acute and longterm stabilization, but are also likely to contribute to chronicity of the otherwise spontaneous clinical course $[14 \bullet, 17,18 \bullet \bullet]$. In other words, if you treat 
a spontaneously episodic recurrent lithium-responsive form of BD with chronic antidepressants or antipsychotics, there is a risk of inducing a more chronic refractory illness course with poor quality of remission [14•].

There is already ample evidence to suggest that, as in other areas of medicine (i.e., cancer), there are identifiable subtypes of BD with different treatment response profiles, and adopting this more individualized approach to treatment has the potential to greatly improve outcomes [19]. For example, despite the current wisdom that early-onset $\mathrm{BD}$ represents a more severe form of illness that likely will require polypharmacy, evidence suggests that even earlyonset disorder can be stabilized with selected monotherapy, chosen on the basis of family history of psychiatric disorders and treatment response in other affected family members, alongside the clinical course of the patient and developmental history [17, 20-22].

\section{Observations from high-risk offspring}

Similar to other major psychiatric and medical illnesses, $\mathrm{BD}$ is a complex trait resulting from the interaction of a number of risk factors in genetically susceptible individuals [23••]. The heritability of $\mathrm{BD}$ is the highest of all psychiatric disorders, estimated at about $85 \%$ [24]. Therefore, studying the biological offspring of affected parents is an important strategy to advance understanding of the onset of illness and to map the early clinical course.

There have been reports from several independent international prospective studies of high-risk offspring that have informed our understanding of risk syndromes predicting the onset of and describing the early clinical course of BD $[25,26 \bullet, 27]$. Specifically, anxiety and sleep disorders (indicative of circadian rhythm disturbance) appear to be early risk syndromes in confirmed high-risk offspring, predicting the later development of major mood episodes [28, 29]. In offspring of parents with a more psychotic spectrum form of $\mathrm{BD}$, childhood risk syndromes also include neurodevelopmental disorders such as learning disabilities and attention deficit hyperactivity disorder $[30 \bullet, 31]$.

BD-related mood disorders in offspring with an affected BD parent are most often in the depressive polarity
$[5,32]$. This, of course, causes a clinical conundrum because, by convention, $\mathrm{BD}$ is not diagnosed until there is a documented activated episode. However, given the overwhelming evidence from clinical, high-risk, and epidemiological studies that BD most often debuts as major depressive episodes, major depression in high-risk offspring is increasingly accepted as the onset of a BD-related mood disorder. This is important because these patients are at greater risk for paradoxical responses to high doses of antidepressants and/or stimulants often prescribed on the basis of presenting clinical symptoms without accounting for family history and likely illness trajectory [33, 34]. This concept is supported by the fact that family studies have estimated that recurrent major depression in first-degree relatives of a $\mathrm{BD}$ patient has an $80 \%$ likelihood of being related to the $\mathrm{BD}$ trait segregating in the family $[35,36]$.

Observations from high-risk studies are consistent with a clinical staging model as articulated by Duffy and colleagues $[37,38]$, which maintains that BD in high-risk individuals (with a first-degree relative with confirmed BD) may be preceded by childhood risk syndromes - including sleep anxiety and, in some cases, neurodevelopmental disorders - followed by minor affective disorders in early adolescence and major mood episodes typically starting in mid to late adolescence. Not all high-risk individuals manifest every stage, but once the illness does manifest, clinically psychopathological development follows this predictable sequence. Specifically, diagnosable activated episodes (BDNOS, BDI, or II) tend to follow the initial depressive episode by several years, and rarely prior to puberty. Of concern is the fact that substance abuse is emerging much earlier in the course than in previous generations, with the drug of choice shifting from alcohol to cannabis [39]. The deleterious effect of substance abuse on the clinical course and treatment response is highly significant, and this complication should be aggressively prevented or treated.

\section{Treatment in high-risk individuals}

As mentioned above, the movement toward earlier diagnosis based on an evidence-informed appreciation of the natural history of psychiatric disorders has advanced the possibility for early intervention and prevention research and clinical practice. However, most of the research to date has focused on 
individuals at high risk for developing schizophrenia and other psychotic disorders $[1 \bullet \bullet, 40,41]$. Nonetheless, this research, in conjunction with findings from studies of the pathophysiology of $\mathrm{BD}$, provides us with an evidential and rational basis from which to develop treatment approaches for clinically unwell individuals at known risk of developing BD and related mood disorders (see Table 1).

\section{Table 1. Treatment approach for clinical stages of developing bipolar disorder}

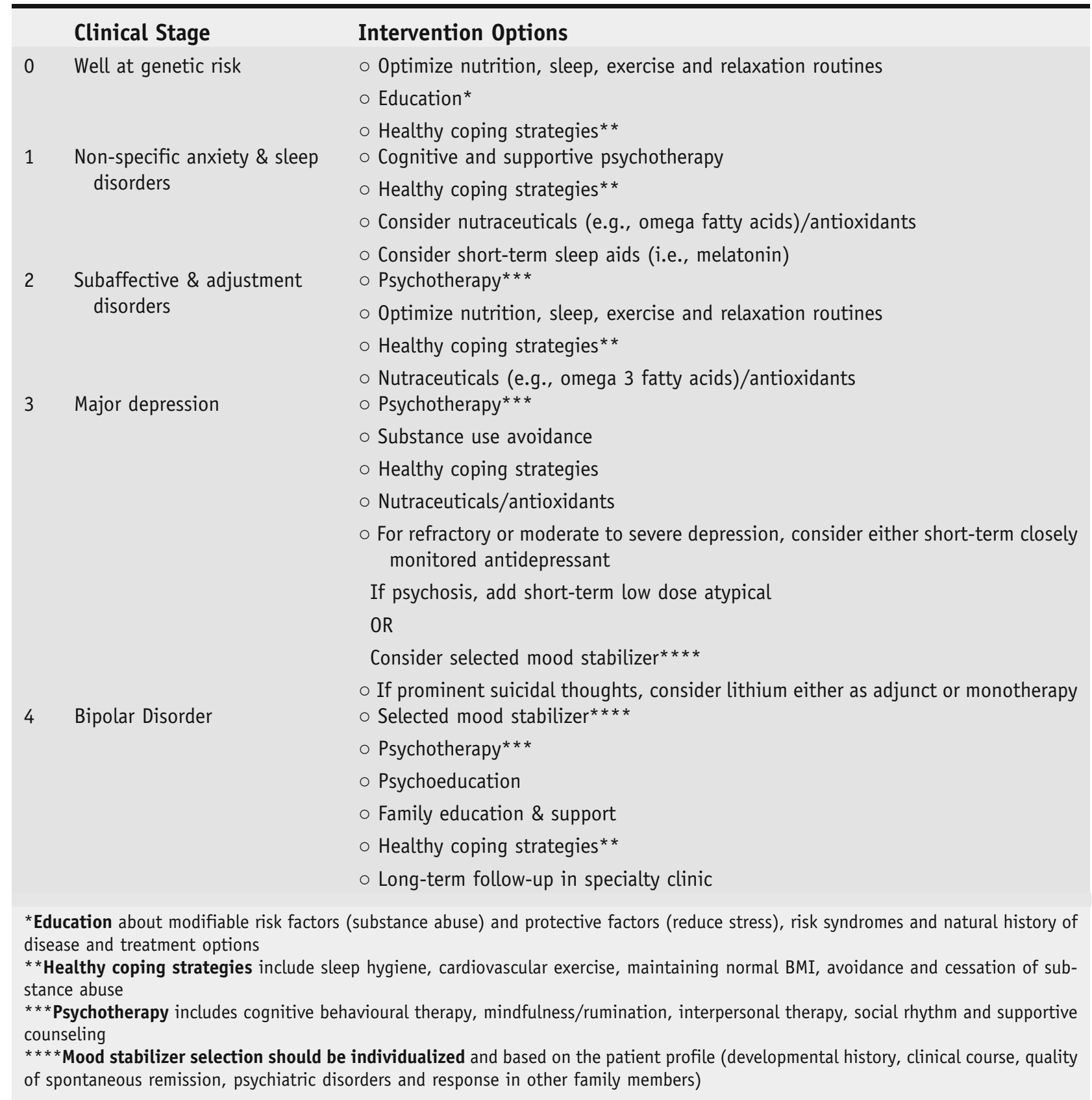


Early-stage treatment - education, healthy lifestyle choices, psychotherapy

It is the logical assumption that intervention earlier in the course of an evolving major psychiatric disorder should have a more favourable benefit/risk ratio [42]. There is accruing evidence that individual and family psychotherapy (CBT, mindfulness-based, supportive) and education is helpful in reducing acute and residual symptoms of anxiety and depression in depressed and bipolar patients [43-45]. More recently, there has been preliminary evidence that these interventions may be helpful in symptomatic high-risk individuals, although more systematic study is needed [46, 47]. In regard to this latter point, there is evidence that cardiovascular exercise, stress reduction intervention, sleep hygiene, and substance abuse prevention all have positive early-

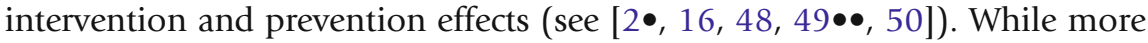
systematic research is needed to understand the underlying mechanisms of the positive effects of these interventions and whether they significantly prevent or delay the progression of $\mathrm{BD}$, it seems reasonable to assume that these low-risk, acceptable, and well-tolerated interventions may be helpful in improving quality of life in the short-term [51].

\section{Early-stage treatments - anti-inflammatory, antioxidants, nutraceuticals}

Since the 1990s, there has been increased recognition of and interest in inflammation as a central genetically sensitive pathway associated with the on-

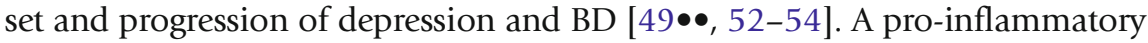
state has been associated with acute mood episodes, and successful treatment has been shown to re-establish the balance between anti- and pro-inflammatory markers $[1 \bullet \bullet, 13 \bullet \bullet, 55]$. Furthermore, recent studies have reported increased expression of inflammation-related genes in offspring of BD parents [56•].This, along with other findings, suggests that subtle abnormalities in the immune system may be present in high-risk offspring [57]. These observations are extremely compelling when taken together with other abnormalities reported in BD patients and their high-risk offspring in the neuroendocrine $[58,59]$ and neurotransmitter systems that are moderated by the

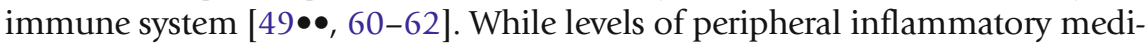
ators are not grossly abnormal (up to two/threefold general population and broadly within normal range), it has been postulated that a mild pro-inflammatory propensity, combined with other risk factors in vulnerable high-risk individuals, may explain the onset and progression of illness [49••]. In addition, over the course of recurrent illness episodes, prolonged inflammatory imbalance may lead to more persistent functional and structural changes

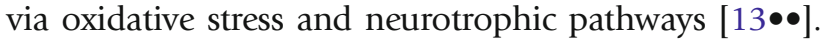

Knowledge regarding the pathways involved in the development and progression of $\mathrm{BD}$ raises the possibility of novel early-intervention approaches and serves as clues for mechanisms of known effective treatments. For example, psychotherapy, meditation, and exercise are associated with a reduction in peripheral inflammatory markers (see $[49 \bullet \bullet, 50])$. There have been some favourable studies of a number of agents with anti-inflammatory properties (i.e., cyclooxygenase-2 inhibitor, TNF inhibitor, acetylsalicylic acid, minocycline) as adjunctive treatments in otherwise-healthy depressed unipolar and bipolar adults $($ see $[2 \bullet, 49 \bullet \bullet, 63])$. As of yet, these interventions have not been systematically studied in high-risk populations. 
There is increasing interest in antioxidant and nutritional supplements due to their safety, acceptability, tolerability, and relevance to the risk of psychiatric and related medical illnesses [64]. Evidence from peripheral and central nervous system samples suggest that disruption in antioxidant enzymes, increased lipid peroxidation activity, and decreased levels of antioxidants (including vitamins $\mathrm{C}, \mathrm{E}$, and $\mathrm{D}$, zinc, and coenzyme Q10) are related to the propensity to psychiatric disease, including depression and $\mathrm{BD}$ [65]. Nacetylcysteine (NAC) has been shown in both basic and clinical studies to reduce markers of oxidative stress and modulate inflammation, with positive effects in bipolar depression when used as an adjunctive treatment $[2 \bullet, 66,67]$. A recent study provided evidence that NAC may be an effective cessation treatment for adolescents with cannabis dependence [68].

The most-studied nutraceuticals with relevance to the prevention and adjunctive treatment of psychiatric disorders are the long-chain omega fatty acids (OFA). OFAs have been shown to have anti-inflammatory, antioxidant, and neuroprotective effects and associated membrane stabilization [69], and to interact with candidate neurotransmitters (serotonin and dopamine) in both basic and clinical studies [70-72]. In a landmark study, a 12-week trial of $1.2 \mathrm{~g} /$ day of long-chain omega-3 polyunsaturated fatty acids (PUFAs) prevented conversion to full-blown psychosis for up to one year in individuals at high risk for psychosis, with a number needed to treat of 4 [73••]. In a recent post hoc analysis, therapeutic effects of this 12-week double-blind placebo-controlled trial were evident by four weeks on positive symptoms and 12 weeks on negative symptoms and global functioning [74].

\section{Treatment of later-stage illness (major mood episodes)}

Treatment of major depressive episodes in an individual at confirmed familial risk of BD is a controversial topic, and also one in need of more systematic study. These episodes typically occur in high-risk individuals who are at least in their adolescence and do not occur in pre-pubescent children. Adolescent depressive episodes in those with a bipolar diathesis have been described as having an abrupt onset, melancholic and psychotic features, and agitation associated with antidepressant treatment $[75 \bullet \bullet, 76]$. Given the lack of substantial evidence directly comparing the risks and benefits of treating adolescent depression as per guidelines or based on the familial risk of $\mathrm{BD}$, it seems reasonable to suggest a trial of psychotherapy administered with either a lowdose short-term antidepressant (plus antipsychotic if psychosis is present), carefully monitored for paradoxical worsening or activation with psychotherapy, or a trial of the minimum effective dose of the mood stabilizer that was effective in the other family members (i.e., lithium, atypical antipsychotic, anticonvulsant) with psychotherapy $[20,21]$.

\section{Continuation treatment and prophylaxis for recurrent mood disorders}

Critical emphasis in treating high-risk youth should be given to involving the patient and family in the treatment plan, which should include a full discussion of potential risks and benefits of any suggested treatment and the state of evidence or lack thereof. The limited data available suggest that the chronic use of antidepressants is not helpful in this population, and sometimes is harmful, associated with chronic depression, rapid cycling, 
or activation. Furthermore, the continuation of mood stabilizers after stabilization of the acute episode needs to be weighed against the recurrence risk, tolerability, acceptability, and effectiveness in individual patients. If the recurrence risk is unknown or of low frequency, a reasonable option would be to discontinue the mood stabilizer after the remission of the acute episode and follow the patient clinically, providing education, support, and counseling, along with incorporation of more benign interventions as described above. Further, biomarkers of illness activity and recurrence risk, such as the dexamethasone suppression test (indicating HPA activation) and peripheral immune markers (immune activation), can be incorporated into the prospective follow-up, along with daily ratings of mood, anxiety, sleep, and energy.

The option of long-term prophylactic medication should be discussed with patients who have an established risk of recurrence. Unselected prophylactic treatment has low success and tolerability rates. Selected prophylactic treatment based on individual patient profile, however, is associated with very high success and tolerability rates [77]. Evidence suggests, for example, that BD patients who respond to long-term lithium prophylaxis are characterized by an episodic remitting illness course, a family history of recurrent mood disorders (not schizophrenia) or poorly remitting psychotic disorders, and a family history of lithium response and classical acute episodes with or without psychosis (lithium has antipsychotic effects) $[78,79]$. Lithium is also very effective in treating suicidal thoughts and behaviour, even as an adjunct in patients who would otherwise not be good long-term responders to lithium monotherapy [10, 14•]. Compliant lithium-responsive patients can often be taken off treatment and monitored for recurrence clinically and biologically, as described above, and restarted at times of high recurrence risk (sleep disruption, depressive or

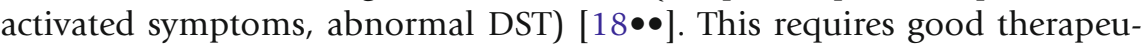
tic alliance and close monitoring. Any medication should be used in conjunction with education, psychotherapy, and exercise, and carefully monitored to prevent weight gain and other medical disorders for which $\mathrm{BD}$ patients are at increased risk, including metabolic syndrome, type II diabetes, and cardiovascular and thyroid disease $([80,81])$.

\section{Conclusion}

A better understanding of the natural history of mood and psychotic disorders has underscored the dramatic unmet need for more vigilant and informed research in earlier identification of serious psychiatric disorders and providing effective and acceptable treatment to alleviate acute suffering and prevent illness progression. Longitudinal studies of high-risk youth has further highlighted that there are reliably identifiable at-risk populations, based on family history or clinical symptoms or both, that should be provided with education and clinical support, preferably with effective interventions that are safe and well-tolerated. While there is a major gap in our knowledge regarding the efficacy of some interventions with a favourable benefit/risk ratio, some evidence exists in the general and other high-risk populations that can inform rational early-interven- 
tion strategies for youth at risk of BD-related mood disorders. Clinical staging lends a conceptual framework that guides these early interventions, as well as future research on associated biomarkers and effectiveness mechanisms. What is astounding to me is that we are still having the same debates about the "risk" of over-labeling and the cost of high-risk surveillance programs, when these would not even be questioned in other areas of medicine, such as cancer care. What is very positive is the increasing recognition in psychiatry of the need for a developmental approach to diagnosis, an essential strategy for advancement of early-stage intervention, and for furthering our understanding of the onset and progression of these disorders.

\section{References and Recommended Reading}

Papers of particular interest, published recently, have been highlighted as:

- Of importance

$\bullet \quad$ Of major importance

1.• McGorry PD, Nelson B, Goldstone S, Yung AR. Clinical staging: a heuristic and practical strategy for new research and better health and social outcomes for psychotic and related mood disorders. Can J Psychiatr Rev Can Psychiatr. 2010;55(8):486-97.

This is a comprehensive review of key findings supporting that clinical staging is an important framework to refine mood and psychotic disorders and includes a discussion of the advantages of this diagnostic approach.

2. Pfaffenseller B, Fries GR, Wollenhaupt-Aguiar B, Colpo GD, Stertz L, Panizzutti B, et al.

Neurotrophins, inflammation and oxidative stress as illness activity biomarkers in bipolar disorder. Expert Rev Neurother. 2013;13(7):827-42.

This is a current concise overview of key candidate biomarkers related to bipolar disorder.

3. Grof P, Alda M, Ahrens B. Clinical course of affective disorders: were Emil Kraepelin and Jules Angst wrong? Psychopathology. 1995;28 Suppl 1:73-80.

This paper provides a cogent discussion as to how the diagnosis of Bipolar Disorder has changed over recent history and highlights the implications for treatment response and clinical course and prognosis.

4. Leboyer M, Henry C, Paillere-Martinot ML, Bellivier F. Age at onset in bipolar affective disorders: a review. Bipolar Disord. 2005;7(2):111-8.

5. Duffy A, Alda M, Hajek T, Grof P. Early course of bipolar disorder in high-risk offspring: prospective study. Br J Psychiatry: J Ment Sci. 2009;195(5):457-8.

6. Angst J, Gamma A, Neuenschwander M, AjdacicGross V, Eich D, Rossler W, et al. Prevalence of mental disorders in the Zurich Cohort Study: a twenty year prospective study. Epidemiol Psichiatr Soc. 2005;14(2):68-76.

7.• Gottesman II, Laursen TM, Bertelsen A, Mortensen PB. Severe mental disorders in offspring with 2 psychiatrically ill parents. Arch Gen Psychiatry. 2010;67(3):252-7.

This paper describes a large population-based study from Denmark showing the risk to age 52 in offspring with either no affected, 1 affected or 2 affected parents with either bipolar disorder or schizophrenia. It demonstrates that bipolar disorder risk is very much determined by a positive family history and that the illness starts to manifest during adolescence. It also demonstrates the importance of taking into account the major depression as part of the bipolar phenotype in at-risk youth.

8. Angst J, Sellaro R. Historical perspectives and natural history of bipolar disorder. Biol Psychiatry. 2000;48(6):445-57.

9.• Trede KS, P.; Baethge, C.; Gerhard, A.; Maggini, C; Baldessarini, R.J. Manic-Depressive Illness: evolution in Kraepelin's Textbook, 1883-1926. Harv Rev Psychiatry. 2005(May/June):155-78.

This is a very thorough and fasincating historical account of the development of Kraepelin's observations and how these shaped his thinking of the natural history of psychiatric illness and the basis upon which he drew categorical divisions.

10. Muller-Oerlinghausen B, Felber W, Berghofer A, Lauterbach E, Ahrens B. The impact of lithium longterm medication on suicidal behavior and mortality of bipolar patients. Arch Suicide Res. 2005;9(3):307-19.

11. Baethge C, Cassidy F. Fighting on the side of life: a special issue on suicide in bipolar disorder. Bipolar Disord. 2013;15(5):453-6. 
12. Baethge C, Baldessarini RJ, Khalsa HM, Hennen J, Salvatore P, Tohen M. Substance abuse in first-episode bipolar I disorder: indications for early intervention. Am J Psychiatry. 2005;162(5):1008-10.

13.• Berk M, Kapczinski F, Andreazza AC, Dean OM, Giorlando F, Maes M, et al. Pathways underlying neuroprogression in bipolar disorder: focus on inflammation, oxidative stress and neurotrophic factors. Neurosci Biobehav Rev. 2011;35(3):804-17.

This paper summarizes the evidence regarding promising neurobiological pathways related to established illness progression and burden of illness in patients with bipolar disorder. The paper focuses on end-stage broadly defined bipolar disorder and highlights the need for such studies in high-risk youth in order to identify primary disease markers and separate these from burden of illness effects.

14. Grof P, Muller-Oerlinghausen B. A critical appraisal of lithium's efficacy and effectiveness: the last 60 years. Bipolar Disord. 2009;11 Suppl 2:10-9.

This is a very concise comprehensive review of the evidence supporting the clinical effectiveness of lithium in various patient populations from the two authors with collectively the most experience using and studing lithium in the world today.

15. Duffy A, Grof P. Psychiatric diagnoses in the context of genetic studies of bipolar disorder. Bipolar Disord. 2001;3(6):270-5.

16. Kapczinski F, Vieta E, Andreazza AC, Frey BN, Gomes FA, Tramontina J, et al. Allostatic load in bipolar disorder: implications for pathophysiology and treatment. Neurosci Biobehav Rev. 2008;32(4): 675-92.

17. Garnham J, Munro A, Slaney C, Macdougall M, Passmore M, Duffy A, et al. Prophylactic treatment response in bipolar disorder: results of a naturalistic observation study. J Affect Disord. 2007;104(1-3):185-90.

$18 . \bullet$ Grof P. Sixty years of lithium responders. Neuropsychobiology. 2010;62(1):8-16.

A very good comprehensive review of a lifetime of work and learning from patients whose lives have been changed through effective treatment with lithium. This is a must read for any professional working with patients who warrant a trial of lithium treatment.

19. Duffy A, Grof P, Robertson C, Alda M. The implications of genetics studies of major mood disorders for clinical practice. J Clin Psychiatry. 2000;61(9):630-7.

20. Duffy A, Alda M, Milin R, Grof P. A consecutive series of treated affected offspring of parents with bipolar disorder: is response associated with the clinical profile? Can J Psychiatr Rev Can Psychiatr. 2007;52(6):369-76.

21. Duffy A, Milin R, Grof P. Maintenance treatment of adolescent bipolar disorder: open study of the effectiveness and tolerability of quetiapine. BMC Psychiatry. 2009;9:4.
22. DA Grof $\mathrm{P}$, Cavazzoni $\mathrm{P}$, et al. Is response to prophylactic lithium a familial trait? J Clin Psychiatry. 2002;63:942-7.

23.• McGuffin P, Perroud N, Uher R, Butler A, Aitchison $\mathrm{KJ}$, Craig I, et al. The genetics of affective disorder and suicide. Eur Psychiatry. 2010;25(5):275-7.

A comprehensive overview of the key findings in genetic studies related to bipolar disorder and suicide.

24. Bienvenu OJ, Davydow DS, Kendler KS. Psychiatric 'diseases' versus behavioral disorders and degree of genetic influence. Psychol Med. 2011;41(1):33-40.

25. DelBello MP, Geller B. Review of studies of child and adolescent offspring of bipolar parents. Bipolar Disord. 2001;3(6):325-34.

26. Duffy A. The early natural history of bipolar disorder: what we have learned from longitudinal high-risk research. Can J Psychiatr. 2010;55(8):477-85.

A comprehensive overview of the key findings and resolved controversies in the pediatric mania debate on the basis of complementary evidence from longitudinal highrisk studies.

27. Mesman E, Nolen WA, Reichart CG, Wals M, Hillegers $\mathrm{MH}$. The Dutch bipolar offspring study: 12-year follow-up. Am J Psychiatry. 2013;170(5):542-9.

28. Duffy A, Horrocks J, Doucette S, Keown-Stoneman C, McCloskey S, Grof P. Childhood anxiety: an early predictor of mood disorders in offspring of bipolar parents. J Affect Disord. 2013;150(2):363-9.

29. Nurnberger JIJ, McInnis M, Reich W, Kastelic E, Wilcox HC, Glowinski A, et al. A high-risk study of bipolar disorder. Childhood clinical phenotypes as precursors of major mood disorders. Arch Gen Psychiatry. 2011;68(10):1012-20.

30. Duffy A, Horrocks J, Doucette S, Keown-Stoneman C, McCloskey S, Grof P. The developmental trajectory of bipolar disorder. Br J Psychiatry: J Ment Sci. 2013.

Summarizes findings in support of a clinical staging model describing the early natural history of bipolar disorder as it develops in high-risk children and adolescents.

31. Duffy A. The nature of the association between childhood ADHD and the development of bipolar disorder: a review of prospective high-risk studies. Am J Psychiatry. 2012;169(12):1247-55.

32. Hillegers MH, Reichart CG, Wals M, Verhulst FC, Ormel J, Nolen WA. Five-year prospective outcome of psychopathology in the adolescent offspring of bipolar parents. Bipolar Disord. 2005;7(4):344-50.

33. Reichart CG, Nolen WA. Earlier onset of bipolar disorder in children by antidepressants or stimulants? An hypothesis. J Affect Disord. 2004;78(1):81-4.

34. DelBello MP, Soutullo CA, Hendricks W, Niemeier RT, McElroy SL, Strakowski SM. Prior stimulant treatment in adolescents with bipolar disorder: association with age at onset. Bipolar Disord. 2001;3(2):53-7. 
35. Blacker D, Lavori PW, Faraone SV, Tsuang MT. Unipolar relatives in bipolar pedigrees: a search for indicators of underlying bipolarity. Am J Med Genet. 1993;48(4):192-9.

36. Winokur G, Tsuang MT, Crowe RR. The Iowa 500: affective disorder in relatives of manic and depressed patients. Am J Psychiatry. 1982;139(2):209-12.

37. Duffy A, Alda M, Hajek T, Sherry SB, Grof P. Early stages in the development of bipolar disorder. J Affect Disord. 2010;121(1-2):127-35.

38. Duffy A, Horrocks J, Milin R, Doucette S, Persson G, Grof $P$. Adolescent substance use disorder during the early stages of bipolar disorder: a prospective high-risk study. J Affect Disord. 2012;142(1-3):57-64.

39. Baethge C, Hennen J, Khalsa HM, Salvatore P, Tohen M, Baldessarini RJ. Sequencing of substance use and affective morbidity in 166 first-episode bipolar I disorder patients. Bipolar Disord. 2008;10(6):738-41.

40. McGorry PD NB, Amminger GP, et al. Intervention in individuals at ultra high risk for psychosis: a review and future directions. J Clin Psychiatry. 2009.

41. Conus P, McGorry PD. First-episode mania: a neglected priority for early intervention. Aust NZ J Psychiatry. 2002;36(2):158-72.

42. Scott J, Leboyer M, Hickie I, Berk M, Kapczinski F, Frank E, et al. Clinical staging in psychiatry: a cross-cutting model of diagnosis with heuristic and practical value. $\mathrm{Br}$ J Psychiatry: J Ment Sci. 2013;202(4):243-5.

43. Watkins ER, Mullan E, Wingrove J, Rimes K, Steiner $\mathrm{H}$, Bathurst N, et al. Rumination-focused cognitivebehavioural therapy for residual depression: phase II randomised controlled trial. Br J Psychiatry: J Ment Sci. 2011;199(4):317-22.

44. Scott J. Psychotherapy for bipolar disorders - efficacy and effectiveness. J Psychopharmacol. 2006;20(2 Suppl):4650.

45. Miklowitz DJ. Functional impairment, stress, and psychosocial intervention in bipolar disorder. Curr Psychiatry Rep. 2011;13(6):504-12.

46. Miklowitz DJ, Schneck CD, Singh MK, Taylor DO, George EL, Cosgrove VE, et al. Early intervention for symptomatic youth at risk for bipolar disorder: a randomized trial of family-focused therapy. J Am Acad Child Adolesc Psychiatry. 2013;52(2):121-31.

47. MiklowitzDJ,ChangKD,TaylorDO,GeorgeEL,SinghMK, SchneckCD, etal.Earlypsychosocialinterventionfor youthatriskforbipolarIorIIdisorder:aone-yeartreatment developmenttrial.BipolarDisord.2011;13(1):67-75.

48. Berk M, Conus P, Kapczinski F, Andreazza AC, Yucel $\mathrm{M}$, Wood SJ, et al. From neuroprogression to neuroprotection: implications for clinical care. Med J Aust. 2010;193(4 Suppl):S36-40.

49.• Raison CL, Miller AH. Is depression an inflammatory disorder? Curr Psychiatry Rep. 2011;13(6):467-75.

This is an excellent summary of the evidence supporting the role of the central and peripheral immune system in the development and recurrence of major depressive episodes and implications for novel treatments.

50. Moylan S, Eyre HA, Maes M, Baune BT, Jacka FN, Berk M. Exercising the worry away: how inflammation, oxidative and nitrogen stress mediates the beneficial effect of physical activity on anxiety disorder symptoms and behaviours. Neurosci Biobehav Rev. 2013;37(4):573-84.

51. Sylvia LG, Friedman ES, Kocsis JH, Bernstein EE, Brody BD, Kinrys G, et al. Association of exercise with quality of life and mood symptoms in a comparative effectiveness study of bipolar disorder. J Affect Disord. 2013;151(2):722-7.

52. Yirmiya R, Goshen I. Immune modulation of learning, memory, neural plasticity and neurogenesis. Brain Behav Immun. 2011;25(2):181-213.

53. Stertz L, Magalhaes PV, Kapczinski F. Is bipolar disorder an inflammatory condition? The relevance of microglial activation. Curr Opin Psychiatry. 2013;26(1):19-26.

54. Gibney SM, Drexhage HA. Evidence for a dysregulated immune system in the etiology of psychiatric disorders. J Neuroimmune Pharmacol. 2013;8(4):900-20.

55. Kauer-Sant'Anna M, Kapczinski F, Andreazza AC, Bond DJ, Lam RW, Young LT, et al. Brain-derived neurotrophic factor and inflammatory markers in patients with early- vs. late-stage bipolar disorder. Int J Neuropsychopharmacol. 2009;12(4):447-58.

56. Padmos RC, Hillegers MH, Knijff EM, Vonk R, Bouvy A, Staal FJ, et al. A discriminating messenger RNA signature for bipolar disorder formed by an aberrant expression of inflammatory genes in monocytes. Arch Gen Psychiatry. 2008;65(4):395-407.

This is an important paper describing novel gene expression findings in pro-inflammatory genes in both parents with bipolar disorder and their high-risk offspring.

57. Duffy A, Lewitzka U, Doucette S, Andreazza A, Grof $P$. Biological indicators of illness risk in offspring of bipolar parents: targeting the hypothalamic-pituitary-adrenal axis and immune system. Early Interv Psychiatry. 2012;6(2):128-37.

58. Hillegers MH, Reichart CG, Wals M, Verhulst FC, Ormel J, Nolen WA, et al. Signs of a higher prevalence of autoimmune thyroiditis in female offspring of bipolar parents. Eur Neuropsychopharmacol. 2007;17(6-7):394-9.

59. Ellenbogen MA, Hodgins S, Linnen AM, Ostiguy CS. Elevated daytime cortisol levels: a biomarker of subsequent major affective disorder? J Affect Disord. 2011; 132(1-2):265-9.

60. Connor TJ, Leonard BE. Depression, stress and immunological activation: the role of cytokines in depressive disorders. Life Sci. 1998;62(7):583-606.

61. Deshauer D, Grof E, Alda M, Grof P. Patterns of DST positivity in remitted affective disorders. Biol Psychiatry. 1999;45(8):1023-9. 
62. Maes M, Ringel K, Kubera M, Berk M, Rybakowski J. Increased autoimmune activity against 5-HT: a key component of depression that is associated with inflammation and activation of cell-mediated immunity, and with severity and staging of depression. J Affect Disord. 2012;136(3):386-92.

63. Goldstein BI, Kemp DE, Soczynska JK, McIntyre RS. Inflammation and the phenomenology, pathophysiology, comorbidity, and treatment of bipolar disorder: a systematic review of the literature. J Clin Psychiatry. 2009;70(8):1078-90.

64. Zhang XY, Yao JK. Oxidative stress and therapeutic implications in psychiatric disorders. Prog NeuroPsychopharmacol Biol Psychiatry. 2013;46:197-9.

65. Pandya CD, Howell KR, Pillai A. Antioxidants as potential therapeutics for neuropsychiatric disorders. Prog Neuro-Psychopharmacol Biol Psychiatry. 2013;46:214-23.

66. Magalhaes PV, Dean OM, Bush AI, Copolov DL, Malhi GS, Kohlmann K, et al. N-acetyl cysteine addon treatment for bipolar II disorder: a subgroup analysis of a randomized placebo-controlled trial. J Affect Disord. 2011;129(1-3):317-20.

67. Berk M, Dean O, Cotton SM, Gama CS, Kapczinski F, Fernandes BS, et al. The efficacy of $\mathrm{N}$-acetylcysteine as an adjunctive treatment in bipolar depression: an open label trial. J Affect Disord. 2011;135(1-3):38994.

68. Gray KM, Carpenter MJ, Baker NL, DeSantis SM, Kryway E, Hartwell KJ, et al. A double-blind randomized controlled trial of $\mathrm{N}$-acetylcysteine in cannabis-dependent adolescents. Am J Psychiatry. 2012;169(8):805-12.

69. Smesny S, Milleit B, Hipler UC, Milleit C, Schafer $\mathrm{MR}$, Klier CM, et al. Omega-3 fatty acid supplementation changes intracellular phospholipase A activity and membrane fatty acid profiles in individuals at ultra-high risk for psychosis. Mol Psychiatry. 2013.

70. Bernardi JR, Ferreira CF, Senter G, Krolow R, de Aguiar BW, Portella AK, et al. Early life stress interacts with the diet deficiency of omega-3 fatty acids during the life course increasing the metabolic vulnerability in adult rats. PLoS One. 2013;8(4):e62031.

71. Andreazza AC, Kapczinski F, Kauer-Sant'Anna M, Walz JC, Bond DJ, Goncalves CA, et al. 3-

Nitrotyrosine and glutathione antioxidant system in patients in the early and late stages of bipolar disorder. J Psychiatry Neurosci. 2009;34(4):263-71.
72. Amminger GP, McGorry PD. Update on omega-3 polyunsaturated fatty acids in early-stage psychotic disorders. Neuropsychopharmacol: Off Publ Am Coll Neuropsychopharmacol. 2012;37(1):309-10.

73.• Amminger GP, Schafer MR, Papageorgiou K, Klier CM, Cotton SM, Harrigan SM, et al. Long-chain omega-3 fatty acids for indicated prevention of psychotic disorders: a randomized, placebo-controlled trial. Arch Gen Psychiatry. 2010;67(2):146-54.

Important randomized placebo controlled 12-week trial of omega-3-fatty acids showing effectiveness in preventing conversion to psychosis in clinically high-risk individuals.

74. Mossaheb N, Schafer MR, Schlogelhofer M, Klier CM, Cotton SM, McGorry PD, et al. Effect of omega-3 fatty acids for indicated prevention of young patients at risk for psychosis: when do they begin to be effective? Schizophr Res. 2013;148(1-3):163-7.

75.• Strober M, Carlson G. Predictors of bipolar illness in adolescents with major depression: a follow-up investigation. Adolesc Psychiatry. 1982;10:299-319. An important sentinel paper identifying clinical predictors of bipolarity in depressed adolescents.

An important sentinel paper identifying clinical predictors of bipolarity in depressed adolescents.

76. Strawn JR, Adler CM, McNamara RK, Welge JA, Bitter SM, Mills NP, et al. Antidepressant tolerability in anxious and depressed youth at high risk for bipolar disorder: a prospective naturalistic treatment study. Bipolar Disord. 2013.

77. Calkin C, Alda M. Beyond the guidelines for bipolar disorder: practical issues in long-term treatment with lithium. Can J Psychiatr Rev Can Psychiatr. 2012;57(7):437-45.

78. Grof P, Duffy A, Alda M, Hajek T. Lithium response across generations. Acta Psychiatr Scand. 2009;120(5):378-85.

79. Berghofer A, Alda M, Adli M, Baethge C, Bauer M, Bschor $\mathrm{T}$, et al. Long-term effectiveness of lithium in bipolar disorder: a multicenter investigation of patients with typical and atypical features. J Clin Psychiatry. 2008;69(12):1860-8.

80. Calkin CV, Gardner DM, Ransom T, Alda M. The relationship between bipolar disorder and type 2 diabetes: more than just co-morbid disorders. Ann Med. 2013;45(2):171-81.

81. Gyulai L, Bauer M, Bauer MS, Garcia-Espana F, Cnaan A, Whybrow PC. Thyroid hypofunction in patients with rapid-cycling bipolar disorder after lithium challenge. Biol Psychiatry. 2003;53(10):899-905. 